\title{
Prehospital interventions to prevent hypothermia in trauma patients: a scoping review
}

\section{AUTHORS}

MAURO MOTA MSCN RN 1,2,3,4,5

MADALENA CUNHA PhD RN 4,5

MARGARIDA SANTOS PhD RN ${ }^{6,7}$

EDUARDO SANTOS MSCN RN1,8,9

FILIPE MELO MSCN RN $33,10,11$

TITO ABRANTES MSC MD ${ }^{12}$

ANA SANTA MSCN RN ${ }^{9}$

\section{CORRESPONDING AUTHOR}

MAURO MOTA Hospital Nossa Senhora da Assunção, Local Health Unit of Guarda, Rua Dona Alexandrina Soares de Albergaria. 6270-498 Seia, Portugal. Phone: +351914973946.

Email: maurolopesmota@gmail.com
1 Abel Salazar Institute of Biomedical Sciences. University of Porto, Porto, Portugal

2 Hospital Nossa Senhora da Assunção, Local Health Unit of Guarda, Seia, Portugal

3 INEM - National Institute of Medical Emergency. Portugal

4 Superior Health School of Viseu, Viseu, Portugal

5 UICISA: E/ESEnfC - Cluster at the Health School of Polytechnic Institute of Viseu, Viseu, Portugal

6 Nursing School of Porto, Porto, Portugal

7 CINTESIS - Center for Health Technology and Services Research, University of Porto, Porto, Portugal

8 Portugal Centre for Evidence-Based Practice: a Joanna Briggs Institute Centre of Excellence

9 Coimbra Hospital and Universitary Centre, Coimbra, Portugal

10 Hospital de Faro. Algarve Hospital and Universitary Centre. Faro, Portugal

11 Hospital São Teotónio, Tondela Viseu Hospital Centre. Viseu, Portugal

11 ABC - Algarve Biomedical Centre. Faro, Portugal

12 Hospital São Teotónio, Tondela Viseu Hospital Centre. Viseu, Portugal

\section{ABSTRACT}

Objective: The aim of this review is to map the prehospital rewarming measures used to prevent hypothermia among trauma victims.

Background: Hypothermia is responsible for an increase of the mortality and morbidity in trauma victims and its recognition and early treatment are crucial for the victim's haemodynamic stabilisation. Prehospital interventions are particularly important, especially those that target bleeding control, haemodynamic stability, and safe body temperature. Registered nurses may be pivotal to prevention and minimisation of the dangerous effects of hypothermia.
Study design and methods: A scoping review was used to identify articles from several online databases from 2010 to 2018. Studies in English, Spanish, and Portuguese were included. Two reviewers performed data extractions independently.

Results: Seven studies were considered eligible for this review: two quantitative research studies, one qualitative research study, and four literature reviews. Rewarming measures can be divided into two main groups: passive rewarming, which includes the use of blankets, positioning the response unit to act as a windbreak, removing the patients' wet clothes, drying the patient's body, and increasing the ambient temperature; and active rewarming which includes the use of heating pads, heated oxygen, 
warmed intravenous fluids, peritoneal irrigation, arteriovenous rewarming, and haemodialysis.

Discussion: Active measures reported by the included studies were always used as a complement to the passive measures. Active rewarming produced an increase in core temperature, and passive rewarming was responsible for intrinsic heatgenerating mechanisms that will counteract heat loss.

Patients receiving passive warming in addition to active warming measures presented a statistically significant increase in body core temperature as well as an improvement in the discomfort caused by cold.

Conclusion: Rewarming measures seem to be essential for the prevention of hypothermia and to minimise the discomfort felt by the patient. In many countries registered nurses can play important roles in the prehospital context of trauma victim's assistance. Greater understanding of these roles is necessary to the development of better practices.

Implications for research, policy, and practice: The findings of this study highlight that passive and active rewarming measures must be implemented as soon as possible for trauma victims. Many measures are incorporated in trauma relief protocols; however, the lack of consensus on their inclusion results in an undervaluation of this issue, which inevitably compromises the safety and wellbeing of trauma victims. In practice, supportive frameworks and an intervention plan (based on heat loss reduction and heat supply) are required to ensure that first responders including registered nurses are able to prevent and treat hypothermia.

\section{What is already known about the topic?}

- Hypothermia is a serious threat to trauma victims in the prehospital context and can induce a "vicious cycle" of hypothermia, acidosis, and coagulopathy.

- To prevent or control the decline of a trauma patient with hypothermia, treatment of hypothermia should ideally begin in the prehospital context.

- Prehospital nurses must be able to develop advanced practice competence to function effectively in their role.

What this paper adds:

- This paper mapped out what measures can be used by prehospital healthcare workers including nurses.

- This study identified all the rewarming measures that may improve the health and wellbeing of patients with hypothermia.

- The combined use of active and passive measures seems to provide better outcomes in the prevention and treatment of hypothermia in trauma victims.

Key words: Multiple trauma; emergency care; nursing; body temperature regulation; warming.

\section{BACKGROUND}

The metabolic imbalance that results from trauma, and the subsequent decrease in oxygen perfusion, is responsible for physiological exhaustion that will take the patient into a "vicious cycle" called Lethal Triad: metabolic acidosis, hypothermia, and coagulopathy. ${ }^{1}$ Hypothermia in trauma victims is clinically important when the body temperature drops below $35^{\circ} \mathrm{C}$ for more than four hours. Hypothermia can

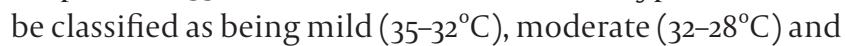
severe $\left(<28^{\circ} \mathrm{C}\right)$. It results from blood loss, patient exposure to the surrounding environment, cold fluids administration and loss of thermoregulatory capacity, common in intoxicated or neurologically damaged victims, and is responsible for ventricular arrhythmias, afterload decrease, increased peripheral vascular resistance, and deviation of the oxygen dissociation curve to the left. ${ }^{2,3}$

Hypothermia affects more than 6o\% of severe trauma victims and is an independent mortality risk factor. In addition to its implications for the cardiovascular, renal and neurological systems, hypothermia also plays a major role aggravating coagulopathy, hence increasing mortality and morbidity. 4 The risk factors for hypothermia are low Glasgow Coma Scale, low air temperature, and a wet patient. ${ }^{5}$ Recognition and early treatment of hypothermia are crucial for the victim's haemodynamic stabilisation.

Prehospital interventions are particularly important, especially the ones promoting bleeding control,

haemodynamic stability and the patient's rewarming. ${ }^{6}$ Rewarming measures should be implemented in prehospital care and involve the use of passive measures - intrinsic heat-generating mechanisms to counteract heat loss - and active rewarming measures. ${ }^{4}$ Since in many countries such as Sweden, Portugal, Finland, Belgium, England, Wales, Spain, and The Netherlands, emergency medical services include nurses in prehospital care, the knowledge and the ability to implement these measures are essential for nurses. These nurses have proven to be important for victims' illness and injury assessment, treatment, and in steering the patient to an optimal level of care. ${ }^{7}$ 
Literature provides little and unclear knowledge about the type of rewarming measures that must be implemented in prehospital settings in order to prevent hypothermia in trauma victims. There is limited evidence on how to implement rewarming interventions, and, in this context, there is a need to perceive not only the kind of interventions that ought to be used, but also if we should use active rewarming measures rather than passive ones, and the situations in which they should be applied. Hypothermia treatment should ideally begin in the prehospital context, with hypothermia wraps, battery-powered inline fluid warmers, ${ }^{6}$ duvets, plastic "bubble wrap", and cotton blankets. ${ }^{8}$ However, there is no consensus about the best way to prevent and treat hypothermia in a prehospital setting. ${ }^{8}$

A scoping review was conducted to systematically map the research carried out on prehospital rewarming measures crucial to prevent hypothermia among trauma victims and to identify the existing knowledge gaps. The following research questions were formulated: Which are the prehospital rewarming measures used to prevent hypothermia in adult trauma victims? What are the characteristics of these rewarming measures? In what contexts/types of trauma have these measures been implemented? In addition, the purpose of this scoping review is to summarise the research findings and identify the existing gaps in the research.

\section{METHOD}

The review was conducted according to the methodology for Joanna Briggs Institute scoping reviews, ${ }^{9}$ and prepared using the PRISMA Extension for Scoping Reviews (PRISMA-ScR) (see Appendix A, Supplementary Data). ${ }^{10}$ The review protocol was established, followed and was previously published. ${ }^{11}$

The search strategy aimed at finding both published and unpublished papers with a three-step search strategy. An initial search, limited to PubMed and CINAHL, identified the articles written on this topic. It was followed by the analysis of the words contained in the titles and abstracts, and of the index terms used to describe those articles. A second search using all previously identified keywords and index terms was carried out in the selected databases: CINAHL Plus with Full Text, PubMed, Cochrane Central Register of Controlled Trials, Scopus, PsycINFO, The JBI Connect+ and Cochrane Database of Systematic Reviews. The search for unpublished studies included: RCAAP - Repositório Científico de Acesso Aberto de Portugal; OpenGrey - System for Information on Grey Literature in Europe. Finally, the reference lists of all the articles identified were analysed. The search strategy for PubMed is presented in Table 1.

\section{TABLE 1: SEARCH STRATEGY FOR PUBMED}

\begin{tabular}{|c|c|}
\hline \#1 & $\begin{array}{l}\text { (((((fracture[Title/Abstract]) OR Dislocation[Title/Abstract]) } \\
\text { OR Dislocation[MeSH Terms]) OR Trauma[MeSH Terms]) OR } \\
\text { (Wounds and Injuries[MeSH Terms])) OR Hypothermia[MeSH } \\
\text { Terms]) OR Shivering[MeSH Terms] }\end{array}$ \\
\hline \#2 & $\begin{array}{l}\text { (((((((Thermal comfort[Title/Abstract]) OR Resistive } \\
\text { Heating[Title/Abstract]) OR Management[Title/Abstract]) } \\
\text { OR rewarm^[Title/Abstract]) OR passive warming OR[Title/ } \\
\text { Abstract]) OR active warming[Title/Abstract]) OR Rewarming } \\
\text { [MeSH Terms]) OR Body temperature regulation[MeSH Terms] }\end{array}$ \\
\hline \#3 & $\begin{array}{l}((((((((((\text { pre-hospital[Title/Abstract]) OR prehospital[Title/ } \\
\text { Abstract]) OR pre hospital[Title/Abstract]) OR } \\
\text { Emergicenters [Title/Abstract]) OR emergency care[Title/ } \\
\text { Abstract]) OR Emergenc [Title/Abstract]) OR Emergency } \\
\text { Health Services[Title/Abstract]) OR Emergency Service, } \\
\text { Hospital[MeSH Terms]) OR Critical Care (MeSH 2018)[MeSH } \\
\text { Terms]) OR Emergency Treatment[MeSH Terms]) OR first } \\
\text { aid[MeSH Terms]) OR emergency responders[MeSH Terms]) } \\
\text { OR Accident[MeSH Terms] }\end{array}$ \\
\hline \#4 & \#1 AND \#2 AND \#3 \\
\hline \#5 & \#4 NOT child* \\
\hline
\end{tabular}

Published and unpublished studies in English, Portuguese and Spanish language, from 01/01/2008 to 31/12/2018 that described all passive and active prehospital rewarming interventions used to prevent hypothermia among trauma patients were considered for inclusion.

Following the search, all identified citations were uploaded into Endnote V7.7.1 (Clarivate Analytics, PA, USA) and the duplicates removed. In order to assess their eligibility, titles and abstracts were screened by two independent reviewers (MM and FM). The full papers were then examined based on the following inclusion criteria:

\section{PARTICIPANTS}

This scoping review considered all studies that focus on adult patients (aged 18 and over) who were victims of trauma. Trauma patients are defined as patients with (suspected) injuries from mechanisms of blunt or penetrating forces, falls, explosions, heat, cold or chemical toxicants. ${ }^{12}$

\section{CONCEPT}

This scoping review considered all rewarming measures implemented and evaluated by health professionals (nurses, physicians and paramedics) in victims of trauma aiming to prevent or treat hypothermia. For this review, rewarming measures included all kinds of treatment performed as emergency care, with the following characteristics: mechanism of action, duration, dose and frequency.

\section{CONTEXT}

Emergency care provided in prehospital settings was considered for inclusion. Care within non-emergency and hospital settings was not eligible for inclusion. 


\section{TYPE OF STUDIES}

This scoping review considered all types of studies, namely systematic reviews, quantitative, qualitative and mixedmethod studies in order to consider different aspects of the rewarming interventions.

Data were extracted by two independent reviewers (MM and TA) from the selected studies using a form that was developed specifically for this review to collect relevant data from each paper and include specific details about the populations, concept, context and the study methods. This form was previously tested by the reviewers before its use (Appendix B, Supplementary Data).

Any disagreement between the reviewers that may have come up during any of the previous steps was resolved with the inclusion of a third reviewer.

The findings were tabulated and accompanied by a narrative synthesis to address the review objective.

\section{RESULTS}

Once duplicates were removed, a total of 1,195 citations were identified from searches in databases. Based on their titles and abstracts, 1,135 were excluded. Sixty full-text articles were retrieved and assessed for eligibility. Of these, 53 were excluded for the following reasons: 27 did not study the main topic, 17 due to intervention, two included children or adolescents and four due to language. Three studies were excluded, as the full text references were unable to be retrieved. The remaining seven studies were considered eligible and included two quantitative research studies, one qualitative research study and four literature reviews. Of the quantitative research studies, one was a randomised control trial and the other a case report. All studies using a qualitative approach were conducted using interviews. Included studies were conducted across six different countries: two were conducted in Sweden, ${ }^{13,14}$ and the remaining undertaken in UK, ${ }^{15}$ South Africa, ${ }^{16}$ Norway, ${ }^{17}$ USA $^{18}$ and Canada ${ }^{4}$.

The study selection is presented in Figure 1.

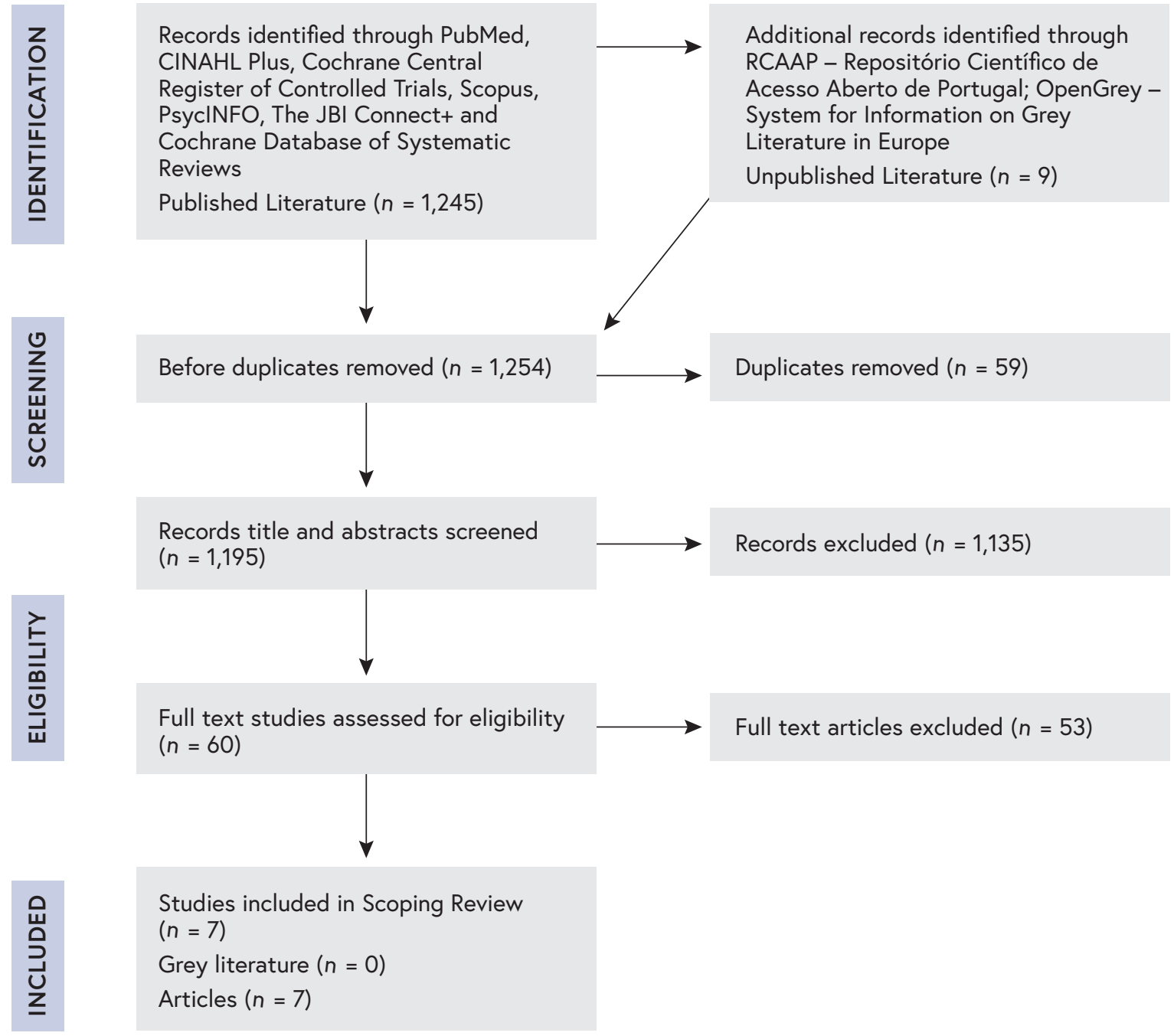


The details and specificities of the included studies are presented in Table 2.

\section{TABLE 2: DETAILS OF INCLUDED STUDIES}

\begin{tabular}{|c|c|c|c|c|}
\hline Authors & Methods & $\begin{array}{l}\text { Participants } \\
\text { characteristics }\end{array}$ & Rewarming measures & Conclusions \\
\hline $\begin{array}{l}\text { Alex and } \\
\text { colleagues } \\
(2013)^{13}\end{array}$ & Interview. & $\begin{array}{l}20 \text { adults injured in the } \\
\text { mountains with several } \\
\text { fractures. Initial body } \\
\text { core temperatures: } \\
32.6^{\circ} \mathrm{C} \text { to } 37.7^{\circ} \mathrm{C} \text {. Outside } \\
\text { temperature: } 4^{\circ} \mathrm{C} \text { to } 14^{\circ} \mathrm{C} \text {. } \\
\text { Wind: windless to } 10 \mathrm{~m} / \mathrm{s} \text {. }\end{array}$ & $\begin{array}{l}\text { Seven victims (mean age of } 39 \text { ) } \\
\text { were treated with passive warming } \\
\text { (blankets). } 13 \text { victims (mean age } \\
\text { of } 55) \text { were treated with passive } \\
\text { warming and active heating pads } \\
(42 \cdot 28 \mathrm{~cm}) .\end{array}$ & $\begin{array}{l}\text { Passive heat applied from beneath } \\
\text { led to a higher heat loss reduction } \\
\text { compared to that applied over the } \\
\text { patients' chest. The heating pads } \\
\text { were described as warm, comfortable } \\
\text { and stopped shivering. Active heat } \\
\text { needed to be applied both from } \\
\text { underneath and on the victim's chest. } \\
\text { Turning up the ambient temperature } \\
\text { inside the ambulance unit is not } \\
\text { effective. }\end{array}$ \\
\hline $\begin{array}{l}\text { Owen and Castle } \\
(2008)^{16}\end{array}$ & Case reports. & $\begin{array}{l}\text { Two patients. An elderly } \\
\text { man had been involved } \\
\text { in a car accident with } \\
\text { an abdominal gunshot } \\
\text { wound and a male } \\
\text { pedestrian involved in a } \\
\text { hit-and-run accident with } \\
\text { several fractures. }\end{array}$ & $\begin{array}{l}\text { Minimised further exposure by } \\
\text { positioning the response unit to act } \\
\text { as a windbreak; Blankets with applied } \\
\text { heating pads and warmed intravenous } \\
\text { (IV) fluids. }\end{array}$ & $\begin{array}{l}\text { Measures have been effectively } \\
\text { increased tympanic temperature } \\
\left(34.0^{\circ} \mathrm{C} \text { to } 35.3^{\circ} \mathrm{C}\right) \text { after } 30 \mathrm{~min} .\end{array}$ \\
\hline $\begin{array}{l}\text { Perlman and } \\
\text { colleagues } \\
(2016)^{4}\end{array}$ & Review. & $\mathrm{n} / \mathrm{a}$ & $\begin{array}{l}\text { Remove wet clothing; Avoid cold } \\
\text { surfaces; Heating blankets (electric } \\
\text { or hot air); Heated intravenous } \\
\text { fluids; Extracorporeal heating } \\
\text { measures (dialysis, peritoneal lavage, } \\
\text { continuous arteriovenous heating - } \\
\text { CAVR); Humidified oxygen. }\end{array}$ & $\begin{array}{l}\text { The early use of warming blankets } \\
\text { and the removal of wet clothing are } \\
\text { recommended, followed by aggressive } \\
\text { rewarming on arrival at the hospital if } \\
\text { the patient's injuries require damage } \\
\text { control therapy. }\end{array}$ \\
\hline $\begin{array}{l}\text { Gill and Cox } \\
(2008)^{18}\end{array}$ & Review. & $\mathrm{n} / \mathrm{a}$ & $\begin{array}{l}\text { Airway rewarming; Blankets } \\
\text { (aluminium, connective and fluid } \\
\text { circulation); Radiant warmer; Body } \\
\text { Cavity Lavage; IV fluids, CAVR. }\end{array}$ & $\begin{array}{l}\text { Central (core) rewarming is by far } \\
\text { the most efficient way to rewarm a } \\
\text { patient. Normothermia is obtained } \\
\text { more quickly through CAVR. Airway } \\
\text { rewarming and aluminium blanket } \\
\text { seem to be the most ineffective } \\
\text { warming methods. }\end{array}$ \\
\hline $\begin{array}{l}\text { Lundgren and } \\
\text { colleagues } \\
(2011)^{14}\end{array}$ & RCT. & $\begin{array}{l}48 \text { blunt trauma patients } \\
\text { with a mean coded } \\
\text { Revised Trauma Score of } \\
7.83 .\end{array}$ & $\begin{array}{l}22 \text { patients receive passive warming } \\
\text { (blankets) and } 26 \text { patients receive } \\
\text { passive warming (blankets + active } \\
\text { warming: chemical heating pad } \\
\text { reaching about } 50^{\circ} \mathrm{C} \text { within two } \\
\text { minutes, applied across the anterior } \\
\text { upper torso). }\end{array}$ & $\begin{array}{l}\text { Additional active warming } \\
\text { significantly improves thermal comfort } \\
\text { even further and might also reduce } \\
\text { the cold-induced stress response. }\end{array}$ \\
\hline $\begin{array}{l}\text { Kornhall and } \\
\text { Martens-Nielsen } \\
(2016)^{17}\end{array}$ & Review. & $\mathrm{n} / \mathrm{a}$ & $\begin{array}{l}\text { Chemical or electrical heating } \\
\text { pads and blankets, applied on } \\
\text { the axillae, chest and back. Bolus } \\
\text { administration of fluids warmed } \\
\text { to } 40-42^{\circ} \mathrm{C} \text {. Insulating materials, } \\
\text { such as sleeping bags, blankets or } \\
\text { bubble wrap. Airtight vapour barrier } \\
\text { immediately outside the wet clothing. } \\
\text { Extracorporeal circulatory support. }\end{array}$ & $\begin{array}{l}\text { Bolus administration of fluids warmed } \\
\text { to } 40-42^{\circ} \mathrm{C} \text { prevents further core } \\
\text { body temperature. } \\
\text { Use of ECC rewarming in hypothermic } \\
\text { avalanche victims in cardiac arrest } \\
\text { or in pure hypothermic cardiac arrest } \\
\text { is associated with extremely poor } \\
\text { outcomes. }\end{array}$ \\
\hline
\end{tabular}


Alex and colleagues sought to verify if active heating measures were more effective than the application of passive measures alone. ${ }^{13}$ The two groups were offered the same model of passive rewarming measures (blankets), and, in one of them, as a supplement, active rewarming with heat pads was also offered. Regarding the passive measures, the two groups reported that their application protected them against the cold; however, the need for a greater supply of heat was also evident. The group that received active rewarming in addition to blankets claimed they felt more comfortable and warmer. In addition, passive measures applied to the back and chest of the victim offered greater comfort and better results in reducing heat loss compared to when they were applied only on the victim's upper torso.

Shivering must be avoided since it increases oxygen demand by up to about $400-500 \%$ of the basal requirement and, ${ }^{19}$ in some studies, it was possible to verify that it only stopped after the heating pad was applied. ${ }^{13}$ Space blankets only led to a limited rise in temperature, on the other hand, heating pads resulted in a body temperature rise by a mean of $0.74^{\circ} \mathrm{C}$ over a 30-minute period. ${ }^{16}$

Despite the increase in body temperature, decrease in cold discomfort, improvement of vital signs and blood pressure, and stabilisation of the patient's heart and respiratory rates; Lundgren and colleagues found that passive heating with blankets is less effective when used alone than when used in addition to active measures. ${ }^{14}$ The use of passive measures combined with active measures showed better results in heating and providing comfort when applied to the victim's back and upper chest. Shivering was corrected only after the application of the heating pads. In patients that were group assigned only to passive warming, initial ear canal mean temperature was $35.1^{\circ} \mathrm{C}$, and at the second measurement, it had increased to $36.0^{\circ} \mathrm{C}$. In the group assigned to active warming, the initial temperature recording was $35.6^{\circ} \mathrm{C}$ and the second was $36.4^{\circ} \mathrm{C}$. In the group assigned to passive and active warming, all 26 patients showed a decrease in the cold discomfort index, whereas in the group assigned for passive warming, only 15 out of the 22 patients presented a decrease in the cold discomfort scale.

In Owen and Castle's opinion, ${ }^{16}$ the first rewarming passive measure is the positioning of a response unit to minimise further exposure. According to these authors, the unit will act as a windbreak.

Preventing further heat loss should be the first concern when approaching the victims, so the removal of wet clothes and the protection of areas such as the victim's head and neck, 4,17 so often neglected, should receive rescuers' special attention. It should be noted that wet clothing removal in a very cold and wet environment will further expose the victim to heat loss by evaporation, a situation that may be minimised by adding an airtight vapour barrier immediately outside the wet clothing. ${ }^{17}$
Increasing ambient temperature does not provide a relevant consensus. ${ }^{13-15}$ For Alex and colleagues rising temperature inside the ambulance did not seem to be as efficient as the heating pads, ${ }^{13}$ however, increasing ambient temperature may be used as a complement to the initial rewarming procedures. ${ }^{14,15}$

Heated intravenous fluids administration continues to raise many questions regarding its effectiveness even though it is integrated within current protocols. ${ }^{16}$ In order to reach acceptable body temperature in people with hypothermia, heated fluids total volume would have to exceed 10 litres, a value that will compromise haemodynamic stability. ${ }^{18,20}$ It should be noted that these fluids do not contribute themselves to the victim's rewarming, ${ }^{18}$ and they should be previously heated to avoid hypothermia worsening. ${ }^{15}$

Heated oxygen, peritoneal irrigation, arteriovenous rewarming and even haemodialysis are potential active internal rewarming measures, ${ }^{15}$ however, there is no evidence of their applicability and efficacy in prehospital settings.

The results also found that rewarming measures are offered regardless of the type of trauma, the type of injuries found and the victims' prognosis; and since hypothermia is responsible for increased pain, anxiety and fear of dying, ${ }^{13}$ it seems that the prompt implementation of rewarming measures is a priority not only to achieve haemodynamic stabilisation ${ }^{14,16,17}$ but also to increase the victims' comfort. ${ }^{13,14}$

\section{DISCUSSION}

Implementing effective rewarming measures for trauma victims in order to prevent and/or treat hypothermia has been an increasing concern for prehospital teams. Thus, it is important to study the measures that should be implemented in prehospital settings and the contexts in which they should be applied. This review aimed to map the existing evidence and to define new lines of research that will support prehospital care providers in assessing the effectiveness of existing passive and active measures.

For the purpose of rewarming, several measures are available. However, there is few or poor evidence related to their applicability, the context of their applicability and which measures should be implemented: passive, active or both. ${ }^{5}$ This work describes existing knowledge covering the different prehospital passive and active rewarming measures used in trauma victims. The results focused mainly on the increase in the core temperature and/or the decrease in cold discomfort. ${ }^{21}$

It is already known that rewarming measures are determinant not only for hypothermia prevention, but also to minimise the discomfort felt by the patient. This discomfort is mainly felt due to the cold being greater than the pain that resulted from the traumatic event. ${ }^{13}$ The thermal sensation that results from the cold was reported by many 
trauma victims as being more uncomfortable than the pain itself. ${ }^{22}$ Furthermore, hypothermia is responsible for a large percentage of mortality among trauma patients when temperature is below $32^{\circ} \mathrm{C}$ and remains poorly handled. ${ }^{4}$

Different mechanisms of heat transfer are responsible for hypothermia: radiation, conduction, convection and evaporation. It is possible to find suitable measures to counteract each of them. To fight radiation one should use a warming blanket, increase ambient temperature, use radiant heaters and avoid unnecessary anaesthesia; to fight conduction, the removal of wet clothing is recommended and nurses should prevent the victim from being in contact with cold surfaces; for convection, nurses should use warming blankets; and for evaporation, one should use humidified gases. , $23^{2}$

Overall, the rewarming measures can be divided into two main groups: passive rewarming that includes the use of blankets, positioning the response unit to act as a windbreak, removing wet clothes and drying the victim's body, and increasing ambient temperature; and active rewarming that uses heating pads, heated oxygen, warmed intravenous fluids, peritoneal irrigation, arteriovenous rewarming and haemodialysis as a last resort. ${ }^{19,27}$

All these measures are relevant and have advantages/ disadvantages, as well as specific conditions to be applied. For example, removing the victim's wet clothing is an important passive rewarming measure, ${ }^{4}$ however, and due to existing environmental conditions, it should be understood that the removal of wet clothing can increase heat loss. In wet and very cold environments, it is suggested not to remove clothing but to place an airtight vapor barrier immediately outside the wet clothing. ${ }^{17}$

Regarding the active warming measures, all included studies used them as complementary measures to the passive ones. Active rewarming produced an increase in core temperature, ${ }^{24}$ and passive rewarming was responsible for intrinsic heat-generating mechanisms that will counteract heat loss. ${ }^{4}$ These measures, when combined, induce a statistically significant increase of the body core temperature as well as an improvement in cold discomfort. ${ }^{14}$

\section{LIMITATIONS}

Our results should be interpreted while taking into account some limitations. First, although we used a rigorous and robust method, the results of this review were intended only to map measures and not to evaluate their effectiveness. On the other hand, this review allows future effectiveness studies to be developed from all the evidence gathered. Second, we are aware that prehospital practices are not always performed by nurses. However, in this case, other clinicians can also obtain relevant information that they can integrate into their practice. At last, the studies included in this review were all developed in extremely cold environments, and in that sense we wondered whether the effectiveness or perception that prehospital teams had of the problem would be the same in "milder" environments; in other words, it remains unanswered whether or not the temperature control is a real concern in prehospital activity during the treatment of trauma victims. Naturally this seems to be a minor problem in certain environments. Hypothermia does not arise exclusively from cold environments, it is a consequence of the pathophysiology of the traumatic event, so hypothermia investigation is necessary for every trauma victim regardless of the ambient temperature.

Based on these findings and analysing the role of nursing in this specific area, it is essential that prehospital care providers develop an intervention plan/operation protocol for hypothermia prevention. This protocol should be based on two fundamental premises: heat loss reduction and heat supply. The first is possible through the implementation of passive rewarming measures and the second through the implementation of active rewarming ones. Even so, these actions should be methodical and not delay the administering of other equally important procedures to the trauma victim, this may include, airway maintenance with cervical spine protection, breathing and ventilation management, circulation assessment and management with haemorrhage control, brief neurological examination and exposure/environmental control. ${ }^{25}$

\section{CONCLUSION}

Hypothermia, in addition of being an important mortality risk factor among trauma victims, is an element that plays an extraordinarily relevant role in these patients' complaints and discomfort.

This review's findings highlight a set of rewarming measures (active and passive) that can be integrated into the practice of prehospital RNs. The combined use of active and passive measures seems to provide better outcomes.

An intervention plan/operation protocol for hypothermia prevention should be developed by prehospital care providers and should integrate two main premises: heat loss reduction and heat supply. Implementation of such a protocol is important in supporting the safety and improvement of trauma patient outcomes.

Future studies should aim at obtaining these different effectiveness measures and understanding which ones are best suited for prehospital settings. In addition, they must be able to respond to two different circumstances: hypothermia prevention in trauma victims and hypothermia treatment in those whose central temperature value is already lower than recommended.

Funding support: This study had no external funding.

Declaration of conflicting interests: Authors declare no conflicts of interest. 


\section{REFERENCES}

1. Johnson MC, Alarhayem A, Convertino V, Carter R, 3rd, Chung $\mathrm{K}$, Stewart $\mathrm{R}$, et al. Comparison of compensatory reserve and arterial lactate as markers of shock and resuscitation. J Trauma Acute Care Surg. 2017;83(4):603-8. Available from: http://www.ncbi.nlm.nih.gov/pubmed/28930955.2017

2. Edelmuth RC, Buscariolli Ydos S, Ribeiro MA, Jr. Damage control surgery: an update. Rev Col Bras Cir. 2013;40(2):14251. Available from: http://www.ncbi.nlm.nih.gov/ pubmed/23752642.2013

3. Pasquier M, Zurron N, Weith B, Turini P, Dami F, Carron PN, et al. Deep accidental hypothermia with core temperature below 24 degrees $\mathrm{c}$ presenting with vital signs. High Alt Med Biol. 2014;15(1):58-63. Available from: http://www.ncbi.nlm.nih.gov/ pubmed/24527793.2014

4. Perlman R, Callum J, Laflamme C, Tien H, Nascimento B, Beckett $A$, et al. A recommended early goal-directed management guideline for the prevention of hypothermia-related transfusion, morbidity, and mortality in severely injured trauma patients. Crit Care. 2016;20(1):107. Available from: http://www.ncbi.nlm.nih. gov/pubmed/27095272.2016

5. Lapostolle F, Couvreur J, Koch FX, Savary D, Alheritiere A, Galinski M, et al. Hypothermia in trauma victims at first arrival of ambulance personnel: an observational study with assessment of risk factors. Scand J Trauma Resusc Emerg Med. 2017;25(1):43. Available from: http://www.ncbi.nlm.nih.gov/ pubmed/28438222.2017

6. Haverkamp FJC, Giesbrecht GG, Tan E. The prehospital management of hypothermia - An up-to-date overview. Injury. 2018;49(2):149-64. Available from: http://www.ncbi.nlm.nih. gov/pubmed/29162267.2018

7. Soren S, Linda W, Veronica L. Development of the Prehospital Emergency Care, The Registered Nurses' Role in the Ambulance Service- A Swedish Perspective. Emergency Med 2015;6(1):294.2015

8. Karlsen AM, Thomassen O, Vikenes BH, Brattebo G. Equipment to prevent, diagnose, and treat hypothermia: a survey of Norwegian pre-hospital services. Scand J Trauma Resusc Emerg Med. 2013;21:63. Available from: http://www.ncbi.nlm.nih.gov/ pubmed/23938145.2013

9. Peters MDJ, Godfrey C, Mclnerney P, Baldini Soares C, Khalil H, Parker D. Chapter 11: Scoping Reviews. In: Aromataris E, Munn Z (Editors). Joanna Briggs Institute Reviewer's Manual, JBI, 2015.

10. Tricco AC, Lillie E, Zarin W, O'Brien KK, Colquhoun H, Levac D, et al. PRISMA Extension for Scoping Reviews (PRISMA-ScR): Checklist and Explanation. Ann Intern Med. 2018;169(7):467-73. Available from: http://www.ncbi.nlm.nih. gov/pubmed/30178033.2018

11. Mota M, Cunha M, Santos MR, Melo F, Santos E. Medidas de Aquecimento na Prevenção da Hipotermia no Pré-Hospitalar a Pessoas Vítimas de Trauma - Protocolo de Revisão Scoping. I Encontro Internacional e VI Encontro Nacional dos Enfermeiros Especialistas em Enfermagem Médico-Cirúrgica: Ordem dos Enfermeiros; 2019. p. 60-1.

12. Galinski M, Ruscev M, Gonzalez G, Kavas J, Ameur L, Biens $D$, et al. Prevalence and management of acute pain in prehospital emergency medicine. Prehosp Emerg Care. 2010;14(3):334-9. Available from: http://www.ncbi.nlm.nih.gov/ pubmed/20507221.2010
13. Alex J, Lundgren P, Henriksson O, Saveman BI. Being cold when injured in a cold environment--patients' experiences. Int Emerg Nurs. 2013;21(1):42-9. Available from: http://www.ncbi.nlm.nih. $\mathrm{gov} / \mathrm{pubmed} / 23273803.2013$

14. Lundgren P, Henriksson $O$, Naredi P, Bjornstig U. The effect of active warming in prehospital trauma care during road and air ambulance transportation - a clinical randomized trial. Scand J Trauma Resusc Emerg Med. 2011;19:59. Available from: http://www.ncbi.nlm.nih.gov/pubmed/22017799.2011

15. Giannoudi M, Harwood P. Damage control resuscitation: lessons learned. Eur J Trauma Emerg Surg. 2016;42(3):273-82. Available from: http://www.ncbi.nlm.nih.gov/pubmed/26847110.2016

16. Owen R, Castle N. Prehospital temperature control. Emerg Med J. 2008;25(6):375-6. Available from: https://emj.bmj.com/ content/25/6/375.long

17. Kornhall DK, Martens-Nielsen J. The prehospital management of avalanche victims. J R Army Med Corps. 2016;162(6):40612. Available from: http://www.ncbi.nlm.nih.gov/ pubmed/26092971.2016

18. Gill BS, Cox CS, Jr. Thermodynamic and logistic considerations for treatment of hypothermia. Mil Med. 2008;173(8):7438. Available from: http://www.ncbi.nlm.nih.gov/ pubmed/18751590.2008

19. Scott EM, Buckland R. A systematic review of intraoperative warming to prevent postoperative complications. AORN J. 2006;83(5):1090-104, 107-13. Available from: http://www.ncbi. nlm.nih.gov/pubmed/16722286.2006

20. Peng RY, Bongard FS. Hypothermia in trauma patients. J Am Coll Surg. 1999;188(6):685-96. Available from: http://www.ncbi.nlm. nih.gov/pubmed/10359364.1999

21. Parsons KC. Thermal comfort. In: Press C, editor. Human thermal environments: the effects of hot, moderate, and cold environments on human health, comfort and performance. 2nd ed. London: UK: Taylor; 2003. p. 196-228.

22. Lundgren P, Henriksson O, Kuklane K, Holmer I, Naredi P, Bjornstig U. Validity and reliability of the Cold Discomfort Scale: a subjective judgement scale for the assessment of patient thermal state in a cold environment. J Clin Monit Comput. 2014;28(3):287-91. Available from: https://www.ncbi.nlm.nih. gov/pmc/articles/PMC4024128/

23. Wilson W, Smith C, Haan J, Elamin E. Hypothermia and heatrelated injuries, Trauma: emergency resuscitation, perioperative anesthesia, surgical management. Boca Raton: CRC Press; 2007.

24. Watts DD, Roche M, Tricarico R, Poole F, Brown JJ, Jr., Colson GB, et al. The utility of traditional prehospital interventions in maintaining thermostasis. Prehosp Emerg Care 1999;3(2):115-22. Available from: http://www.ncbi.nlm.nih.gov/ pubmed/10225643.1999

25. American College of Surgeons ACS. Advanced Trauma Life Support - Student Course Manual. 9 ed. Chicago. 2012. 